\title{
A Contribution to the Knowledge of Ancient Pre-Hispanic Au-Pt Processes
}

\author{
M. E. Noguez, G. Villegas, G. Salas, T. Robert, and J. Ramírez \\ Facultad de Química, Departamento de Ingeniería Metalúrgica, \\ Universidad Nacional Autónoma de México, México, D.F., 04510, México.
}

P. Bergsoe (1937) expressed the sintering process to make Au-Pt objects from alluvial Au and Pt deposits in pre-Hispanic times (400BC-400AD) in South America. It was by melting Au particles around the Pt ones and then heating and hammering [1]. Since then the interested archaeometallurgists, included the authors of this work, have assumed this method as the logic and most probable [2]. Handwerker et al. (1991) came out with the suspicious that pre-Hispanic artisans people might have not reached the liquid phase in the process of making the alloys [3]. P. Bergsoe also proposed a process to make Pt clad alloys: heating two previously made alloys, one rich in Pt and the other rich in gold, then hammering out with a few intervals for annealing [1]. D. Scott (1994) observed a clad alloy under the microscope and proposed that plating can also be produced by laying Pt particles on the gold, heating to allow them to fuse and then finishing with light hammering. He reported a laboratory experiment [4]. N. Meeks et al. (2002), observing a pre-Hispanic clad alloy, deduced the use of two alloys in its making, as Bergsoe [5].

In this work, the authors have first simulated a sintering process for the production of an $85 \% \mathrm{Au}-$ $15 \%$ Pt alloy (weight percent). Tiny particles of Au and Pt (1x2x0.5mm, Fig. 2) commercially pure were used, without reaching the liquid phase. Diffusion cycles which include heating at $920^{\circ} \mathrm{C}$ then hot and cold hammering, starting at $730^{\circ} \mathrm{C}$ until $100^{\circ} \mathrm{C}$, folding and heating again for $10 \mathrm{~h}$ at $950^{\circ} \mathrm{C}$ were giving. The cycles are exhibited in figure 1 . There it can be seen the diffusion time, the strokes, the folding steps, and the variation in composition obtained during the process. The final equilibrium analysis was $82 \% \mathrm{Au}-18 \% \mathrm{Pt}$. This simulation represents an experimental proof that solid state diffusion by itself can be used to make a desired alloy. As for our knowledge this has not been reported before. Figure 2 belongs to different stages on the making process.

The clad alloy process was simulated by laying Pt small particles $(1 \times 2 \times 0.5 \mathrm{~mm})$ on the anvil then covering them with a foil of an $82 \% \mathrm{Au}-18 \% \mathrm{Pt}$ alloy. Hot and cold hammering with the same temperature variations as in the sinter was applied until the surface of the foil was coated with Pt. Then it was annealed $4 \mathrm{~h}$ at $950^{\circ} \mathrm{C}$. Pt particles sintered between them and with the gold alloy. The Pt clad alloy process is the same as in Scott [4] but in a more logical way, giving the strokes on the golden foil, not on the Pt particles. This is the first time that macroscopic and optical microscope images of simulated Pt-Au clad are presented. Figure 3 illustrates the obtained clad alloy.

The above experimental simulations widen our view of the technologies that could have been used and prepare us to be open minded to more findings.

Authors are grateful to Guillermina Mancera for the SEM work.

References

[1] P. Bergsoe, The Metallurgy and Technology of Gold and Platinum Among the PreColumbian Indians, DNKS Copenhagen, 1937.

[2] M.E. Noguez et al., JOM, 58, (2006) 38. 
[3] C.A. Handwerker et al., Mat. Res. Soc. Symp. Proc., 185 (1991) 649.

[4] D.A. Scott and W. Bray, Archaeometry of the Pre-Columbian Sites, Proceeding of the Symposium organized by the UCLA Institute of Archaeology and the Getty Conservation Institute, 1994, p. 285.

[5] N. Meeks, S. La Niece and P. Estévez, Archaeometry, 44 (2002) 273.

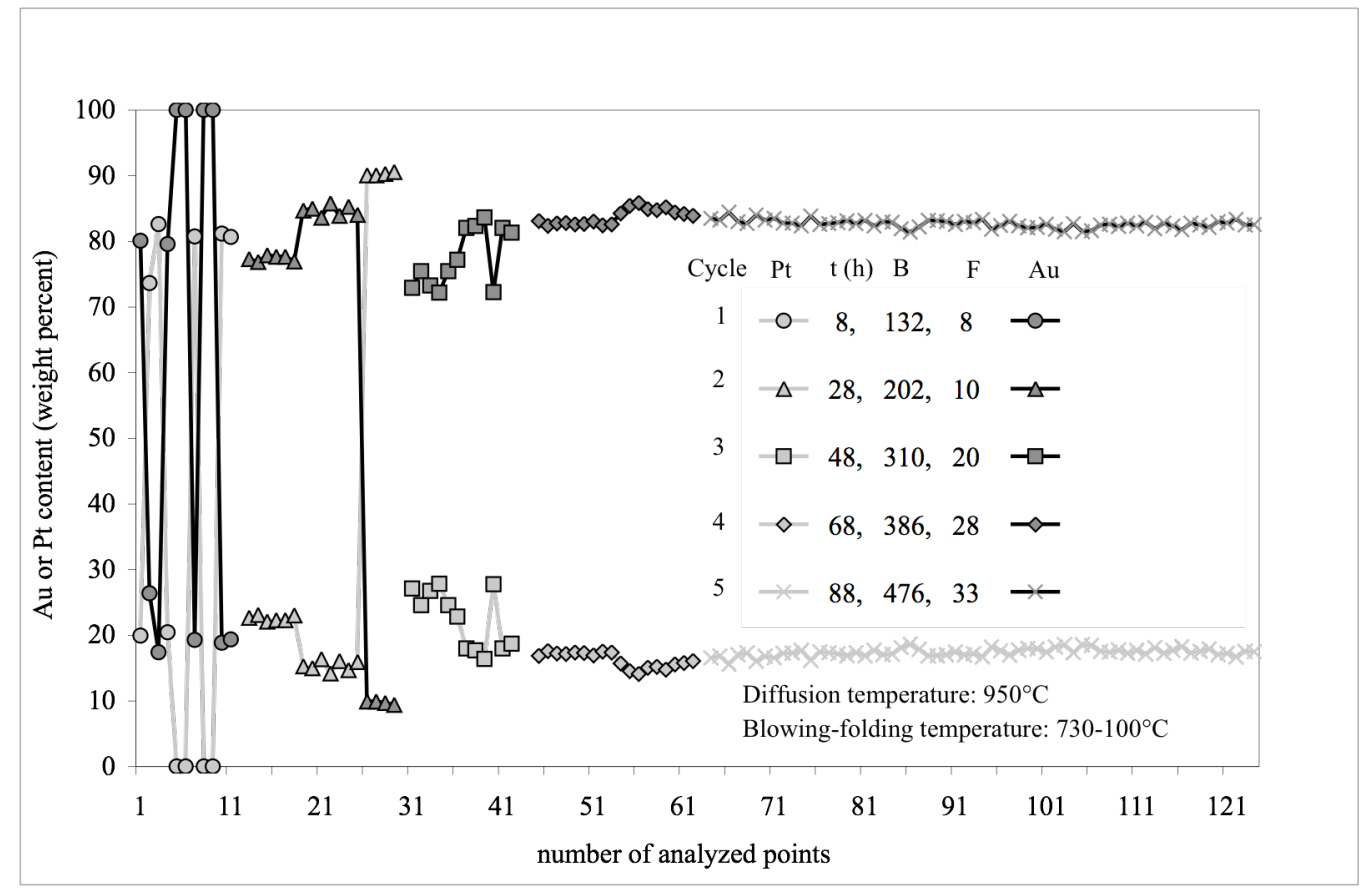

Fig. 1. Punctual microanalysis of each cycle in the process of sintering the alloy showing the cumulative diffusion times $(\mathrm{t})$, the number of blows $(\mathrm{B})$, and the number of foldings $(\mathrm{F})$.

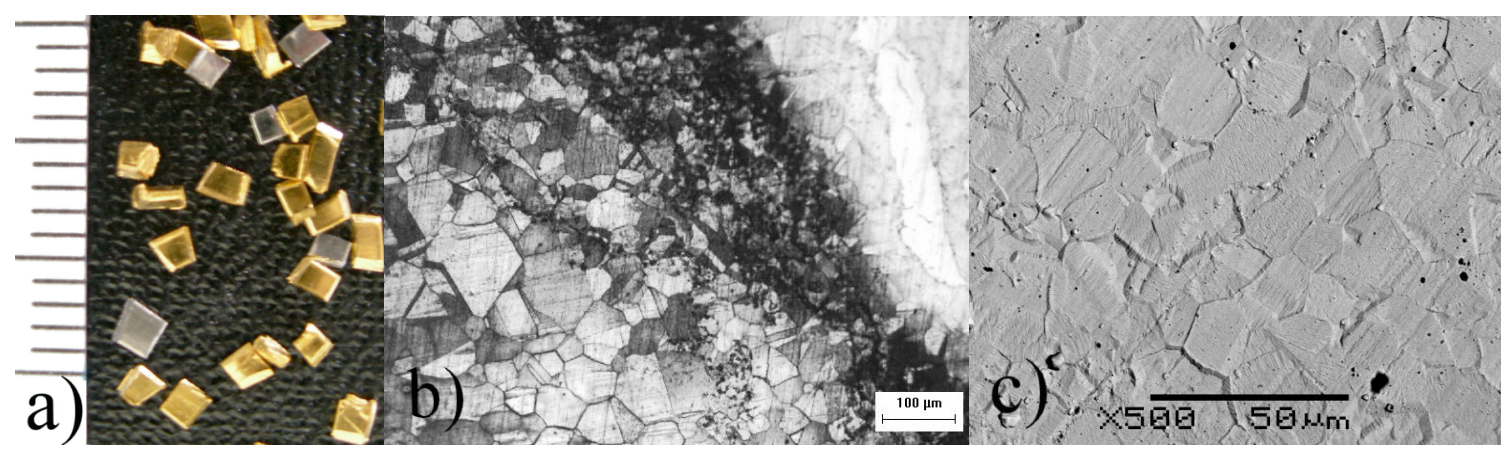

Fig. 2. Sintered alloy. a) Au and Pt particles used as raw materials (rule in mm). b) Intermediate process optical microstructure. c) Final homogeneous SEM microstructure.

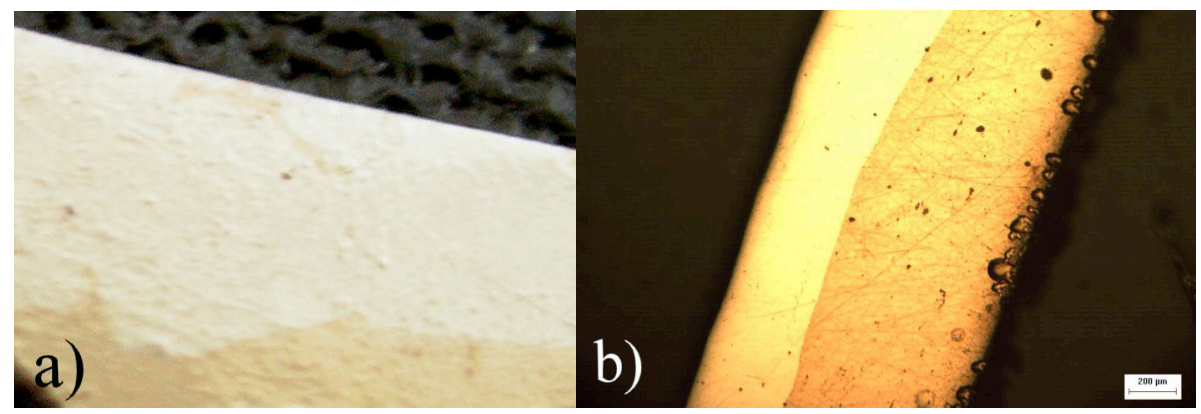

Fig. 3. Clad alloy. a) Macrostructure showing Pt (upper) over Au rich alloy (lower).

b) Optical microstructure of same piece ( $\mathrm{Pt}$ at left, $\mathrm{Au}$ at right). 